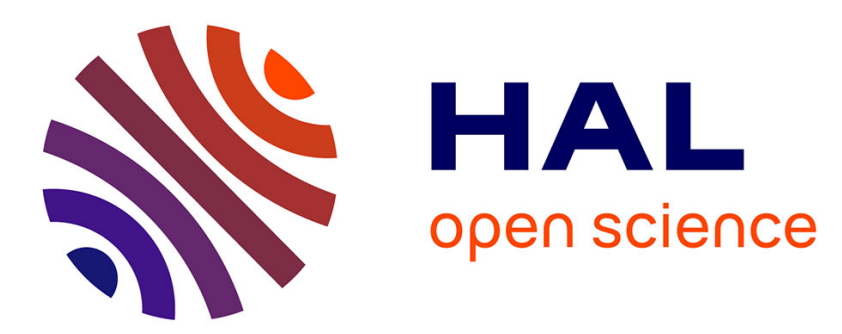

\title{
Silicate surface coverage controls quinolone transport in saturated porous media
}

Lian Zhou, Wei Cheng, Remi Marsac, Jean-François Boily, Khalil Hanna

\section{To cite this version:}

Lian Zhou, Wei Cheng, Remi Marsac, Jean-François Boily, Khalil Hanna. Silicate surface coverage controls quinolone transport in saturated porous media. Journal of Colloid and Interface Science, 2022, 607, pp.347-356. 10.1016/j.jcis.2021.08.142 . insu-03325535

\section{HAL Id: insu-03325535 \\ https://hal-insu.archives-ouvertes.fr/insu-03325535}

Submitted on 25 Aug 2021

HAL is a multi-disciplinary open access archive for the deposit and dissemination of scientific research documents, whether they are published or not. The documents may come from teaching and research institutions in France or abroad, or from public or private research centers.
L'archive ouverte pluridisciplinaire HAL, est destinée au dépôt et à la diffusion de documents scientifiques de niveau recherche, publiés ou non, émanant des établissements d'enseignement et de recherche français ou étrangers, des laboratoires publics ou privés. 


\section{Journal Pre-proofs}

Silicate surface coverage controls quinolone transport in saturated porous media

Lian Zhou, Wei Cheng, Rémi Marsac, Jean-François Boily, Khalil Hanna

PII:

S0021-9797(21)01370-9

DOI:

https://doi.org/10.1016/j.jcis.2021.08.142

Reference:

YJCIS 28673

To appear in:

Journal of Colloid and Interface Science

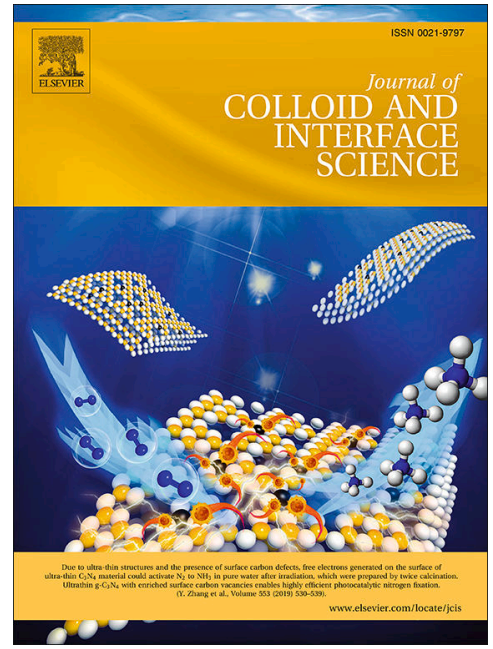

Received Date: $\quad 30$ March 2021

Revised Date: $\quad 19$ August 2021

Accepted Date: $\quad 21$ August 2021

Please cite this article as: L. Zhou, W. Cheng, R. Marsac, J-F. Boily, K. Hanna, Silicate surface coverage controls quinolone transport in saturated porous media, Journal of Colloid and Interface Science (2021), doi: https:// doi.org/10.1016/j.jcis.2021.08.142

This is a PDF file of an article that has undergone enhancements after acceptance, such as the addition of a cover page and metadata, and formatting for readability, but it is not yet the definitive version of record. This version will undergo additional copyediting, typesetting and review before it is published in its final form, but we are providing this version to give early visibility of the article. Please note that, during the production process, errors may be discovered which could affect the content, and all legal disclaimers that apply to the journal pertain.

(C) 2021 Published by Elsevier Inc. 


\title{
Silicate surface coverage controls quinolone transport in saturated porous
}

\section{media}

\author{
Lian Zhou ${ }^{1,2}$, Wei Cheng, ${ }^{1,2}$, Rémi Marsac ${ }^{3}$, Jean-François Boily ${ }^{2}$, Khalil Hanna ${ }^{1,4 *}$
}

${ }^{1}$ Univ Rennes, Ecole Nationale Supérieure de Chimie de Rennes, UMR CNRS 6226, 11 Allée de Beaulieu, F35708 Rennes Cedex 7, France.

${ }^{2}$ Department of Chemistry, Umeå University, Umeå, SE-901 87, Sweden.

${ }^{3}$ Univ Rennes, CNRS, Géosciences Rennes - UMR 6118, F-35000 Rennes, France.

${ }^{4}$ Institut Universitaire de France (IUF), MESRI, 1 rue Descartes, 75231 Paris, France.

*Corresponding author: +332232380 27, khalil.hanna@ensc-rennes.fr 


\section{Abstract}

Although silicates are the most common anions in aquatic systems, little is known on the roles they play on the transport of emerging contaminants, such as antibiotics. Using dynamic column experiments, we revealed the controls of Si loadings on goethite $(\alpha-\mathrm{FeOOH})$ coated sands on the transport of a widely used quinolone antibiotic, here focusing on Nalidixic Acid (NA). We find that dynamic flow-through conditions $(2.98 \mathrm{~cm} / \mathrm{h}$ and $14.92 \mathrm{~cm} / \mathrm{h})$ sustain monomeric Si species with loadings of up to $\sim 0.8 \mathrm{Si} / \mathrm{nm}^{2}$ but that oligomeric species can form at the goethite surfaces under static (batch, no-flow conditions). While these monomeric species occupy no more than $\sim 22 \%$ of the reactive $\mathrm{OH}$ groups on goethite, they can effectively suppress NA binding, and therefore enhance NA mobility in dynamic conditions. NA can also bind on goethite when it is simultaneously injected with high concentrations of Si (2000 $\mu \mathrm{M})$, yet it becomes progressively replaced by Si over time. Combining kinetics and surface complexation modeling, we present a new transport model to account for the stepwise polymerization of Si on goethite and NA transport. Our findings show that dissolved Si common to natural surface waters can play a determining role on the surface speciation and transport of antibiotics in the environment.

Keywords: reactive transport; modeling; silicate; polymersiation; adsorption. 


\section{INTRODUCTION}

Silicate $(\mathrm{Si})$ is one of the major oxyanions in soils, surface waters and groundwater, with concentrations in the sub- to low-millimolar range (e.g. 0.17-1.24 $\mathrm{mM} \mathrm{[1,2]).} \mathrm{Generally,} \mathrm{the} \mathrm{downward} \mathrm{infiltration} \mathrm{of} \mathrm{water}$ through soils releases silica from weatherable silicate minerals [3]. Si concentrations relate to water residence times, the type of silicate minerals contacted by water, mineral surface area and $\mathrm{pH}$ [4-6]. The resulting dissolved and mobile Si then binds onto reactive soil mineral constituents, such as Fe(oxy)(hydr)oxides [7-10]. Because these binding mechanisms modify surface site availability, surface charge and phase transformation [7,11-13], they can effectively impede binding of anthropogenic compounds and/or toxic elements $[14,15]$, thus promoting their mobility in the environment $[1,16]$.

Figure 1. Schematic representation of possible configurations of Si monomers, dimers and oligomers on goethite on the (a) (101) and (b) (010) faces of goethite. Ideally, Si binding begins with ligand exchange with reactive, singly-coordinated, $-\mathrm{OH}$ groups (三 $\mathrm{FeOH}^{-0.5}$ in text), then follows by dimerization and oligomerization at the surface. $\mu_{3}-\mathrm{OH}$ groups are unexchangeable triply-

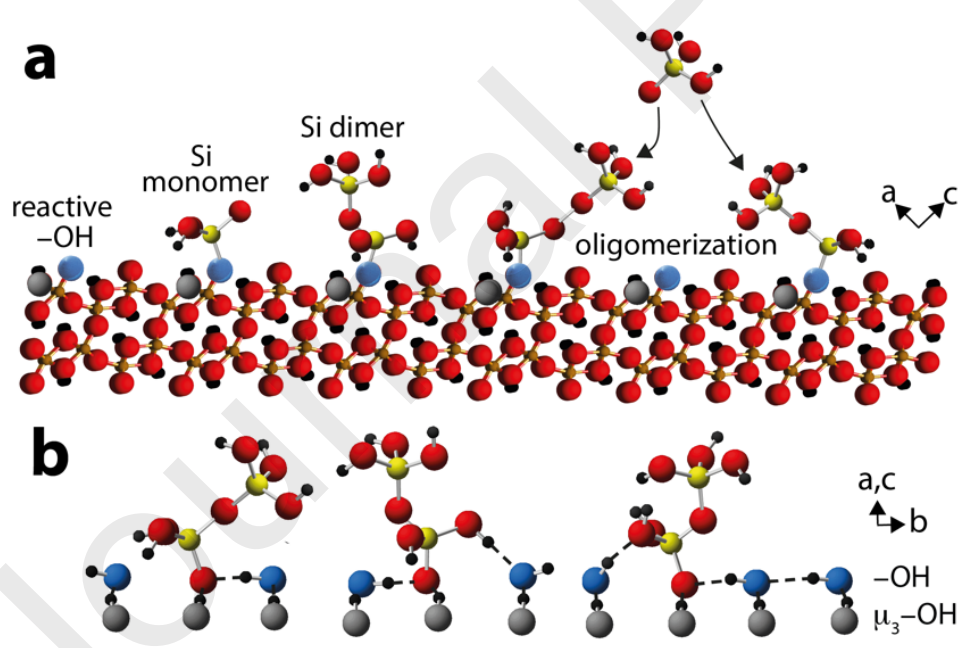

coordinated groups.

Si binding to goethite $(\alpha-\mathrm{FeOOH})$ is expected to take place first through ligand exchange with reactive $\mathrm{OH}$ groups $\left(=\mathrm{FeOH}^{-0.5}\right)$ (Fig. 1) groups at $<1 \mathrm{Si} / \mathrm{nm}^{2}$, enabling formation of rows of mononuclear monodentate silicate species, each separated by at least one [17]. Subsequently, these surface species are 
attachment sites from which oligomerization and polymerization reactions occur. On goethite, these reactions occur at loadings exceeding $\sim 1 \mathrm{Si} / \mathrm{nm}^{2}[17]$ (Figure 1). These binding mechanisms are also affected by $\mathrm{pH}$, surface orientation and ageing time [15], whereas steric constraints play also an important role on the availability of $\mathrm{OH}$ groups for ligand exchange and that of other populations of (hydr)oxo groups $[3,18]$. Although these binding mechanisms have been investigated [3,18,19], little is known about the impact of silica surface speciation on the interactions of co-existing organic compounds with mineral surfaces. In addition, most studies have focused on the reactivity of silicate coatings towards contaminants under batch and equilibrated suspensions $[2,14,15]$. Little is, however, known on how contaminant transport is affected under dynamic, flow-through, conditions that are far more prevalent in nature. Knowledge of the controls that Si concentration and contact time play on surface loadings of monomeric, oligomeric and polymeric species is needed to explore this important question.

In this study, we begin by investigating silicate retention in goethite-coated sand (GCS) columns, which are chosen to emulate groundwater and surface water environments. Goethite was selected as model mineral because it is one of the most thermodynamically stable iron oxyhydroxide under ambient conditions, and the most abundant one in natural settings. We then assessed the transport of Nalidixic acid (NA), a quinolone antibiotic widely used in human and veterinary medicine [20,21], in (i) GCS columns in absence or presence of Si in the influent solution, and (ii) Si-preloaded columns resulting by exposure solutions of $100-2000$ $\mu \mathrm{M} \mathrm{Si}$. These conditions were chosen to mimic two situations where target contaminants (i) are present together with silicates in groundwater and surface waters, then compete for binding sites on mineral surfaces, and (ii) where they interact with silicate coatings on mineral surfaces.

In this work, a new kinetic term was implemented together with a surface complexation model (SCM) in the widely used geochemical modeling code PHREEQC-2 [22] to predict the breakthrough behavior of 
NA and Si under dynamic conditions. This combined modeling approach explains how silica surface coverage affects the breakthrough behavior of NA. This work additionally explains how molecular interactions between silicate and mineral surfaces control quinolone transport in surface and subsurface environments.

\section{RESULTS AND DISCUSSION}

\section{MATERIALS AND METHODS}

2.1. Materials. All solutions were prepared with ultrapure water in Nalgene flasks with no contact with glass surfaces during preparation to prevent silica contamination. Briefly, a $1 \mathrm{mM}$ stock solution of NA (Sigma, purity $>99 \%$ ) was prepared by dissolving $1 \mathrm{mmol} \mathrm{NA}$ in $20 \mathrm{~mL}$ of $1 \mathrm{M} \mathrm{NaOH}$ and then diluting to 1 $\mathrm{L}$ with ultrapure water, as previously reported in Cheng et al.[23]. Stock solutions of 0.1, 0.5, 1 and-2 mM $\mathrm{Na}_{2} \mathrm{SiO}_{3} \cdot 9 \mathrm{H}_{2} \mathrm{O}$ (Sigma, $>99 \%$ ) was prepared in $0.01 \mathrm{M} \mathrm{NaCl}$. Fourier Transform Infrared (FTIR) spectra of these silicate-bearing solutions did not have any clearly resolvable bands indicative of monomeric and/or polymeric species. However, from the study of Halasz et al.[24], where $80 \%$ of the species were monomeric in solutions of $0.2 \mathrm{M} \mathrm{Na}_{2} \mathrm{SiO}_{3} \cdot 9 \mathrm{H}_{2} \mathrm{O}$, polymeric species likely represent a very small proportion in the $0.1-2$ $\mathrm{mM}$ silicate solutions used for this work.

Finally, quartz sand from Fontainebleau $\left(100-150 \mu \mathrm{m}, \sim 0.06 \mathrm{~m}^{2} / \mathrm{g}\right)$ was purchased from Carlo Erba. The sand was washed with $\mathrm{HCl}, \mathrm{H}_{2} \mathrm{O}_{2}$ and then with pure water several times to remove impurities. The detailed procedure is given in the Supporting Information (SI). 
2.2. Column experiments. Continuous flow experiments were conducted at room temperature and under water-saturated conditions. Columns $(1.6 \mathrm{~cm}$ internal diameter $)$ were packed with $15 \mathrm{~g}$ of dry goethitecoated sand (GCS), providing bed length of $4.9 \pm 0.1 \mathrm{~cm}$. The bulk density of the packed sand is $1.52 \pm 0.05$ $\mathrm{g} / \mathrm{cm}^{3}$. Goethite and GCS were synthesized as described in previous studies [25-28], and as summarized in

SI. The possible dissolution of the used quartz sand was checked in sand suspensions with two solid loadings, 1 or $10 \mathrm{~g} / \mathrm{L}$, under stirring and aged for one month and at various equilibrium $\mathrm{pH}$ (4-10), in pure water or $0.01 \mathrm{M} \mathrm{NaCl}$ solution. The amount of dissolved silicate was below the detection limit (molybdenum blue spectrophotometric method (detection limit $1 \mu \mathrm{M}$ ) and ICP/AES (detection limit 0.2 $\mu \mathrm{M})$ ), for all experimental conditions of this study.

The goethite content deposited on the sand surface, measured by acid digestion analysis, was $0.98 \mathrm{~g} / 100$ $\mathrm{g}$ of sand. The columns were wetted upward with a $0.01 \mathrm{M} \mathrm{NaCl}$ solution at flow rate $0.5 \mathrm{~mL} / \mathrm{min}$ (Darcy velocity of $14.92 \mathrm{~cm} / \mathrm{h}$ ) for $24 \mathrm{~h}$ to reach water-saturated condition. The pore volume (PV) of GCS columns, here determined by weight, was $3.7 \pm 0.1 \mathrm{~mL}$. Once the column was saturated, flow characteristics of the porous bed were determined by injecting a nonreactive tracer (a $2 \mathrm{~mL}$ pulse of $0.05 \mathrm{M} \mathrm{NaBr}$ ) at flow rate of $0.5 \mathrm{~mL} / \mathrm{min}$. The tracer experimental breakthrough curve (Fig. S2) was then determined by continuous online conductivity measurement of effluent, and then confirmed by ionic chromatographic analysis of BrThe fitting parameters of the bromide elution, obtained through the classical advection-dispersion equation (ADE), confirmed flow homogeneity and the predominance of a convective regime. The mass balance ratios calculated based on BTCs of $\mathrm{Br}^{-}$were close to $100 \%$ (Fig. S2). The hydrodynamic parameters estimated includes total water content, $\theta(0.363 \pm 0.005)$, and dispersivity, $\lambda(0.25 \pm 0.01 \mathrm{~cm})($ See Table $\mathrm{S} 1)$.

After the pulse tracer experiments, four sets of column experiments were firstly performed by stepinjection of different concentration of Si solutions $(100,500,1000,2000 \mu \mathrm{M} \mathrm{Si}$ in $0.01 \mathrm{M} \mathrm{NaCl})$ at 0.5 
$\mathrm{mL} / \mathrm{min}$. To investigate the influence of rate-limited sorption process, column experiments were conducted with a step injection (i) at two different Si concentrations (100 $\mu \mathrm{M}$ and $1000 \mu \mathrm{M}$ Si in $0.01 \mathrm{M} \mathrm{NaCl})$, (ii) at lowered flow rate $(0.1 \mathrm{~mL} / \mathrm{min}$; Darcy velocity of $2.98 \mathrm{~cm} / \mathrm{h})$, or (iii) by interrupting flow (i.e. $0 \mathrm{ml} / \mathrm{min}$ ) when the effluent concentration reached a steady-state value $\left(C / C_{0} \geq 0.99\right)$. Different flow-interruption periods ( $1 \mathrm{~d}, 3 \mathrm{~d}, 30 \mathrm{~d})$ were tested in separate column experiments or during the same experiment through a repeated flow-no flow-flow sequence, as previously reported [29]. For pre-loading experiments, we preequilibrated the column with increasing influent concentration of $\mathrm{Si}(100,500$ and $2000 \mu \mathrm{M} \mathrm{Si})$. To obtain larger Si loadings $\left(\sim 1.30 \mathrm{Si} / \mathrm{nm}^{2}\right)$, we interrupted the flow for 2 days for the highest Si inflow concentration $(2000 \mu \mathrm{M})$. More details about column experiments are given in Table S2. All influent solutions were adjusted to $\mathrm{pH} 5.0 \pm 0.1$ which is the equilibrium $\mathrm{pH}$ after column saturation, and purged with $\mathrm{N}_{2}(\mathrm{~g})$ throughout the course of the experiment to avoid $\mathrm{CO}_{2}$ contamination.

NA concentrations in the collected fractions were determined by a high performance liquid chromatography (HPLC) system, equipped with an auto sampler (Waters 717 plus), using a C18 column ( $250 \mathrm{~mm} \times 4.6 \mathrm{~mm}$ i.d., $5 \mu \mathrm{m}$ ) and a UV detector operating at $258 \mathrm{~nm}$ (Waters 2489). The mobile phase was a mixture of water/acetonitrile $(60: 40 \mathrm{v} / \mathrm{v})$ containing $0.1 \%$ of formic acid. The flow rate of the mobile phase was set at $1 \mathrm{~mL} / \mathrm{min}$ in isocratic mode. Dissolved silicate was determined with the molybdenum blue spectrophotometric method (detection limit $1 \mu \mathrm{M}$ ) [30]. Continuous on-line $\mathrm{pH}$ measurement was performed using pre-calibrated $\mathrm{pH}$ flow through sensor. In addition, the $\mathrm{pH}$ of collected fractions was often checked using a pH-meter (HI2210, HANNA $\left.^{\circledR}\right)$. All experiments were conducted in at least duplicates (triplicates for batch experiments and duplicates for column tests), and the estimated uncertainty was given in the caption of each figure. 
2.3. Surface complexation modeling. In a previous study [20], we showed that NA binds to goethite through metal-bonded (MB), H-bonded (HB), and outer-sphere (OS) complexes (See SI for more details). Spectroscopic and theoretical studies showed that silicates form MB complexes and oligomers/polymers at goethite surfaces [8,31]. Si binding from solutions of monomeric Si species first produce monomeric MB complexes resulting from a ligand exchange reaction with singly coordinated hydroxo $\left(\equiv \mathrm{FeOH}^{-0.5}\right)$ groups. These can produce mononuclear monodentate or mononuclear bidentate species. Oligomerization and polymerization reactions occur when monomer silicates attach to existing MB Si species at high Si surface loading $\left(\sim 1 \mathrm{Si} / \mathrm{nm}^{2}\right)$ [17]. According to a recent spectroscopic investigation [17], a Si mononuclear monodentate complex may coexist with other adjacent non-exchangeable groups. This was recently confirmed for the adsorption of Si monomers on ferrihydrite and described in the Charge Distribution MultiSIte Complexation (CD-MUSIC) model [32] as a mononuclear monodentate H-bond option [18]. We here used CD-MUSIC model to predict the formation monomer silicates species on goethite with a binuclear bidentate silicate species, which is similar in stoichiometry to a mononuclear monodentate also forming a hydrogen bond with a neighboring group. Oligomeric species are, in turn, predicted using a tetrameric silicate species. The surface complexation reactions of all surface species are reported in Table S3. The MUSIC model approach [33] and geochemical speciation code PHREEQC-2 [22] were used for calculations. The charge of the goethite/water interface was treated by using the three-plane model (TPM). Charges of the adsorbates were distributed among the $0\left(\mathrm{H}^{+}, \mathrm{MB}\right), 1(\mathrm{HB})$, and $2\left(\mathrm{Na}^{+}, \mathrm{Cl}^{-}, \mathrm{OS}\right)$ planes of the TPM. Singly $\left(\equiv \mathrm{FeOH}^{-0.5}\right)$, doubly $\left(\equiv \mathrm{Fe}_{2} \mathrm{OH}\right)$ and triply $\left(\equiv \mathrm{Fe}_{3} \mathrm{O}^{-0.5}\right.$ and $\left.\equiv \mathrm{Fe}_{3} \mathrm{OH}^{+0.5}\right)$ coordinated sites outcrop the goethite surface, depending on the crystal face. A simplified 1-pK surface charging model, neglecting the contributions of doubly- and part of the triply-coordinated sites was used. The reactive site density is given as detailed in our previous work $[34]$ : $\left[\equiv \mathrm{FeOH}^{-0.5}\right]=3.12$ sites $/ \mathrm{nm}^{2}$ and $\left[\equiv \mathrm{Fe}_{3} \mathrm{O}^{-0.5}\right]=3.12$ sites $/ \mathrm{nm}^{2}$ on 
$(001) /(101)$ planes $\left(90 \%\right.$ of the surface area), and $\left[\equiv \mathrm{FeOH}^{-0.5}\right]=7.4$ sites $/ \mathrm{nm}^{2}$ on $(210) /(010)$ plane $(10 \%$ of the surface area). The protonation constants of these groups are set to that of the $\mathrm{pH}_{\mathrm{pzc}}(1-\mathrm{pK}$ approximation approach of MUSIC model). All the calculations used the "minteq v4" database.

\subsection{Implementation of kinetics in surface complexation reactions}

OS complexes of organic ligands form more quickly than inner sphere (IS) complexes [20,35,36] because the expulsion of water from the inner hydration shell can be rate-limiting [37]. As an attempt to integrate kinetics in SCM, we assume surface complexation reactions occur in two steps: (i) formation of precursor surface species (fast intermediate step) and (ii) formation of final surface species (rate-limiting step). According to previous work [20] and our ATR-FTIR data (See Fig. S1), NA can form MB, HB and OS complexes as follows:

$2 \mathrm{H}^{+}+2 \equiv \mathrm{FeOH}^{-0.5}+\mathrm{NA}^{-} \rightleftharpoons\left(\equiv \mathrm{FeOH}_{2}\right)_{2}^{+} \cdot \cdots \cdot \mathrm{NA}^{-}(\mathrm{OS}$ complexes $)$

$2 \mathrm{H}^{+}+2 \equiv \mathrm{FeOH}^{-0.5}+\mathrm{NA}^{-} \rightleftharpoons\left(\equiv \mathrm{FeOH}_{2}\right)_{2}{ }^{+} \cdots \mathrm{NA}^{-}(\mathrm{HB}$ complexes $)$

$2 \mathrm{H}^{+}+2 \equiv \mathrm{FeOH}^{-0.5}+\mathrm{NA}^{-} \rightleftharpoons(\equiv \mathrm{Fe})_{2}\left(\mathrm{NA}^{0}\right)+2 \mathrm{H}_{2} \mathrm{O}$ (MB complexes)

According to a previous spectroscopic study [36] showing the conversion of hydrogen-bonded organic species to metal-bonded complexes was time-dependent, HB and OS complexes can be considered as intermediate species in the proposed conceptual model. To distinguish the two-step reactions in PHREEQC2, we defined one intermediate ' $\mathrm{NA}$ in' and one equilibrium ' $\mathrm{NA}$ ' species. Here, ' $\mathrm{NA}$ ' ' is an intermediate complex first in the form of a OS species:

$2 \mathrm{H}^{+}+2 \equiv \mathrm{FeOH}^{-0.5}+\mathrm{NA}^{\text {in- }} \rightleftharpoons\left(\equiv \mathrm{FeOH}_{2}\right)_{2}{ }^{+} \cdot \cdot \mathrm{NA}^{\text {in- }}(\mathrm{OS}$ formation $)$

It then converts to a HB species through:

$2 \mathrm{H}^{+}+2 \equiv \mathrm{FeOH}^{-0.5}+\mathrm{NA}^{\text {in- }} \rightleftharpoons\left(\equiv \mathrm{FeOH}_{2}\right)_{2}{ }^{+\cdots} \cdot \mathrm{NA}^{\text {in- }}(\mathrm{HB}$ formation $)$ 
The resulting HB species then converts to a MB through:

$\left(\equiv \mathrm{FeOH}_{2}\right)_{2}{ }^{+} \cdots \mathrm{NA}^{\text {in- }}(\mathrm{HB}) \stackrel{\mathrm{K}_{\mathrm{f}}}{\underset{\mathrm{K}_{\mathrm{b}}}{\rightleftharpoons}}\left(\equiv \mathrm{FeOH}_{2}\right)_{2}{ }^{+\cdots} \mathrm{NA}^{-}(\mathrm{HB})$

$\mathrm{K}_{\mathrm{f}}$ and $\mathrm{K}_{\mathrm{b}}$ are forward and backward rate coefficients $\left(\mathrm{T}^{-1}\right)$ respectively, which could be obtained by curve fitting.

According to the Si binding mechanisms on goethite [17], Si surface reactions could be also assumed to occur in two steps similar with NA, among which the Si surface oligomerization reaction is the ratedetermining step. To mimic the step-wise growth of Si polymers on goethite, monomeric species were defined as $\mathrm{Si}^{*}(\mathrm{OH})_{4}$ and $\mathrm{Si}(\mathrm{OH})_{4}$ in the database. $\mathrm{Si}^{*}(\mathrm{OH})_{4}$ is proposed to form an intermediate monomeric surface complex through the reaction:

$$
2 \equiv \mathrm{FeOH}^{-0.5}+\mathrm{Si}^{*}(\mathrm{OH})_{4}{ }^{0} \rightleftharpoons(\equiv \mathrm{FeO})_{2} \mathrm{Si}^{*}(\mathrm{OH})_{2}{ }^{-}+2 \mathrm{H}_{2} \mathrm{O}
$$

As for Si, both binuclear bidentate silicate species and tetramer silicates could be formed:

$\equiv \mathrm{FeOH}^{-0.5}+\mathrm{Si}(\mathrm{OH})_{4}{ }^{0} \rightleftharpoons(\equiv \mathrm{FeO})_{2} \mathrm{Si}(\mathrm{OH})_{2}{ }^{-}+2 \mathrm{H}_{2} \mathrm{O}$

$2 \equiv \mathrm{FeOH}^{-0.5}+4 \mathrm{Si}(\mathrm{OH})_{4}{ }^{0} \rightleftharpoons(\equiv \mathrm{FeO})_{2} \mathrm{SiOHOSi}_{3} \mathrm{O}_{3}(\mathrm{OH})_{9}{ }^{-}+4 \mathrm{H}_{2} \mathrm{O}$

$2 \equiv \mathrm{FeOH}^{-0.5}+4 \mathrm{Si}(\mathrm{OH})_{4}{ }^{0} \rightleftharpoons(\equiv \mathrm{FeO})_{2} \mathrm{SiOHOSi}_{3} \mathrm{O}_{4}(\mathrm{OH})_{8}{ }^{2-}+\mathrm{H}^{+}+4 \mathrm{H}_{2} \mathrm{O}$

The kinetic conversion equation of $(\equiv \mathrm{FeO})_{2} \mathrm{Si}^{*}(\mathrm{OH})_{2}{ }^{-}$species to $(\equiv \mathrm{FeO})_{2} \mathrm{Si}(\mathrm{OH})_{2}{ }^{-}$species was used to described the stepwise Si surface oligomerization:

$(\equiv \mathrm{FeO})_{2} \mathrm{Si}^{*}(\mathrm{OH})_{2}{ }^{-} \stackrel{\mathrm{K}_{\mathrm{f}}}{\underset{\mathrm{K}_{\mathrm{b}}}{\rightleftharpoons}}(\equiv \mathrm{FeO})_{2} \mathrm{Si}(\mathrm{OH})_{2}{ }^{-}$

$\mathrm{K}_{\mathrm{f}}$ and $\mathrm{K}_{\mathrm{b}}$ are forward and backward rate coefficients $\left(\mathrm{T}^{-1}\right)$ respectively. 
2.5. Modeling solute transport. Since SCM describes sorption based on surface reaction equilibrium, this method could be applied when surface reactions reached local equilibrium or, at least, were not significantly affected by chemical nonequilibrium. When non-equilibrium conditions prevailed, implementation of kinetics in surface complexation reactions was needed. In this study, SCM with equilibrium and nonequilibrium reactions was coupled with advection-dispersion transport model in PHREEQC-2 to simulate the breakthrough curves of NA with and without Si. The aqueous concentrations of target chemicals are governed by the following advection-reaction-dispersion (ARD) equation [22]:

$$
\frac{\partial C}{\partial t}=-v \frac{\partial C}{\partial x}+D_{\mathrm{L}} \frac{\partial^{2} C}{\partial x^{2}}-\frac{\partial q}{\partial t}
$$

where $C$ is concentration in water $\left(\mathrm{M} / \mathrm{L}^{3}\right), t$ is time $(\mathrm{T}), v$ is pore water flow velocity $(\mathrm{L} / \mathrm{T}), x$ is distance $(\mathrm{L})$, $D_{\mathrm{L}}$ is the hydrodynamic dispersion coefficient $\left(\mathrm{L}^{2} / \mathrm{T}\right)$, and $q$ is concentration in the solid phase (expressed as $\mathrm{M} / \mathrm{L}^{3}$ in the pores). Transport modeling was performed with the geochemical model PHREEQC-2. The numerical approach in PHREEQC-2 follows the basic components of ARD equation in a split-operator scheme [22]. First, advective transport was calculated, followed by calculation of equilibrium and kinetically controlled chemical reactions, and dispersive transport. The chemical interaction term $\frac{\partial q}{\partial t}$ calculated separately from the transport part for each time step is the sum of all equilibrium and non-equilibrium reaction rates. 


\section{RESULTS AND DISCUSSION}

\subsection{Si binding under non-equilibrium conditions}

Batch experiments (Fig. 2) revealed a 5 d-period of rapid Si uptake by goethite, followed by a slower period over the following $25 \mathrm{~d}$. Kinetic modeling of these data ( $c f$. SI and Tables S3 and S5 for details) was achieved using monomeric and oligomeric species (Eq. 7-11; Table S3), and with forward and backward rate coefficients of Si oligomerization of $0.234( \pm 0.103) \mathrm{h}^{-1}$ and $0.128( \pm 0.048) \mathrm{h}^{-1}$, respectively. The model suggests an onset for Si oligomerization after $\sim 15 \mathrm{~h}$ of reaction time (Fig. 2a). Si sorption edges under batch conditions (Fig. 2b) were also predicted using the same three surface complexation reactions (Table S3; $c f$. Tables S4-S5 for details). The data and model revealed Si surface loadings from $\sim 0.64 \mathrm{Si} / \mathrm{nm}^{2}$ at $100 \mu \mathrm{M} \mathrm{Si}$ to $\sim 1.75 \mathrm{Si} / \mathrm{nm}^{2} 1000 \mu \mathrm{M}$ at $\mathrm{pH} 5$, and these are in agreement with previous batch data $[2,8]$.

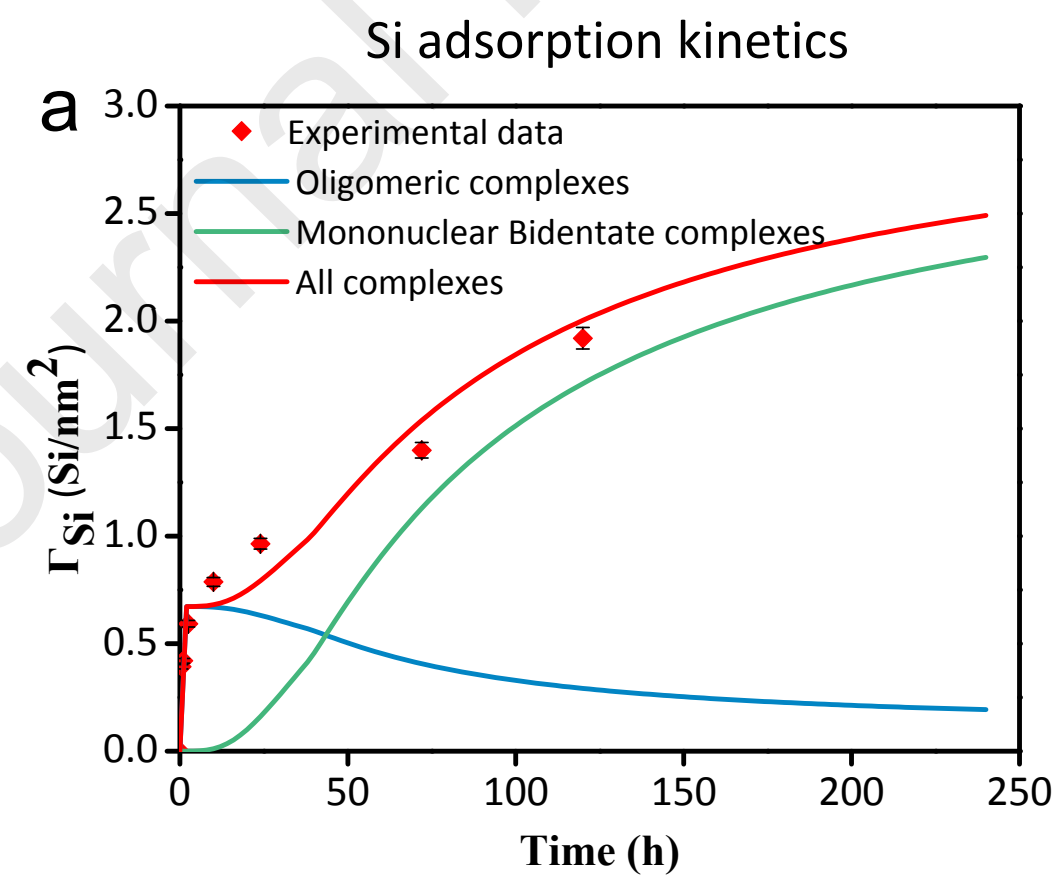




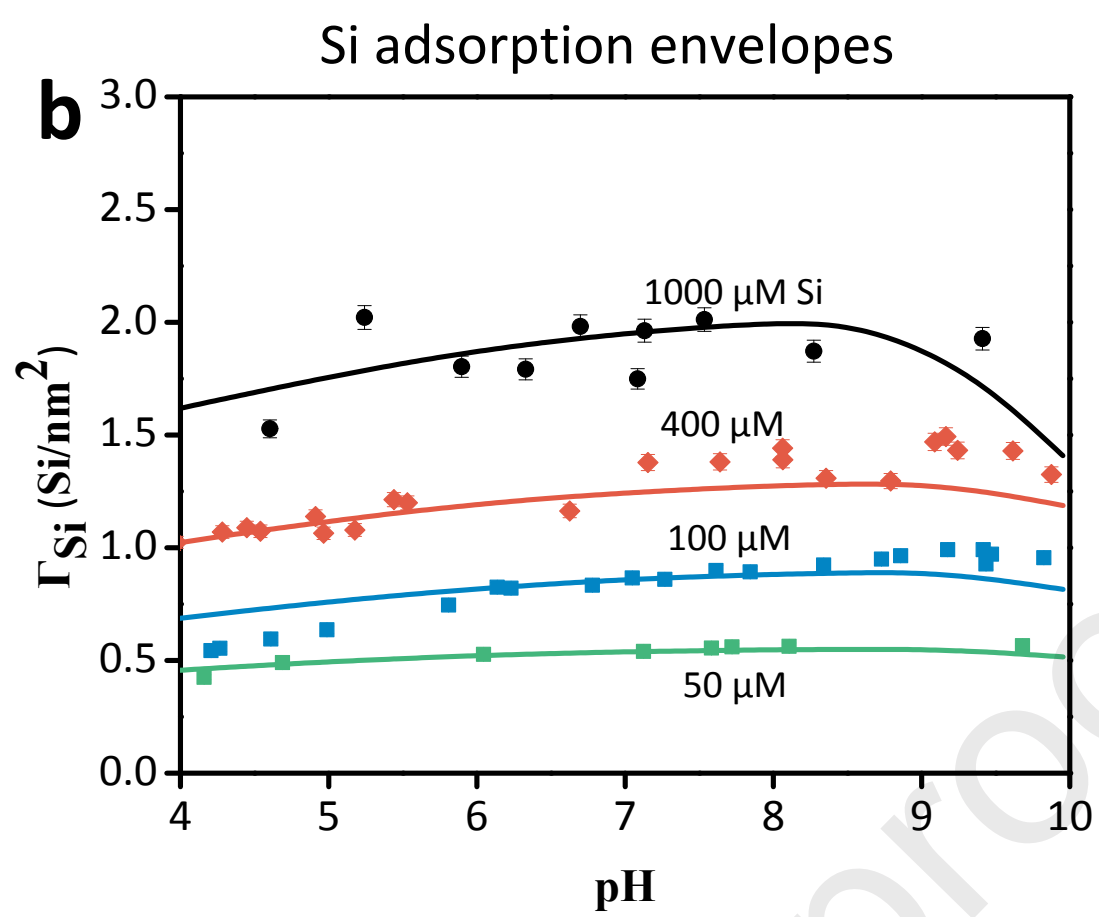

Figure 2. (a) Batch adsorption kinetics of $\mathrm{Si}$ on goethite at $\mathrm{pH} 5 \pm 0.1$ (initial $[\mathrm{Si}]=1000 \mu \mathrm{M}$, background electrolyte $0.01 \mathrm{M}$ $\mathrm{NaCl}$, room temperature). (b) $\mathrm{pH}$-dependence of Si binding on goethite in batch (solid/solution ratio $=50 \mathrm{~m}^{2} / \mathrm{L}, \mathrm{Background}$ electrolyte $0.01 \mathrm{M} \mathrm{NaCl}$, reaction time $1 \mathrm{~d}$ at room temperature). Solid lines are surface complexation modeling results. $\Gamma_{\mathrm{Si}}$ stands for Si surface loading. The estimated relative uncertainty for batch data lied at $3 \%$.

$\mathrm{Si}$ adsorption onto goethite under dynamic flow conditions was then investigated at various influent $\mathrm{Si}$ concentrations $(100,500,1000,2000 \mu \mathrm{M})$. The shape and positions of breakthrough curves (BTCs) resulted from a complex mix of equilibrium and non-equilibrium adsorption and dispersion/diffusion processes.

Here, increased influent Si concentrations from 100 to $2000 \mu \mathrm{M}$ induced a downshift of the breakthrough point, and more symmetrically-shaped breakthrough curve (BTC) (Fig.3). Si surface loadings, estimated by integrating the area above the $\mathrm{BTC}$, ranged from $\sim 0.25 \mathrm{Si} / \mathrm{nm}^{2}$ in $100 \mu \mathrm{M}$ to $\sim 0.78 \mathrm{Si} / \mathrm{nm}^{2}$ in $2000 \mu \mathrm{M}$ and represent no more than $22 \%$ of the reactive $\equiv \mathrm{FeOH}^{-0.5}$ density $\left(\sim 3.5\right.$ sites $\left./ \mathrm{nm}^{2}\right)$ on goethite. Additionally, because these loadings were up to $\sim 3$ times lower than those obtained by batch adsorption (Fig. $2 \mathrm{~b}$ ) and because our previous work [17] showed no oligomerization Si surface loadings below $1 \mathrm{Si} / \mathrm{nm}^{2}$, we suspect that dynamic flow inhibited oligomerization. We contend that changes in resident Si concentrations and/or 
from kinetic limitations due to a short residence time could account for lower Si loading in dynamic than in static (batch, no-flow) conditions.
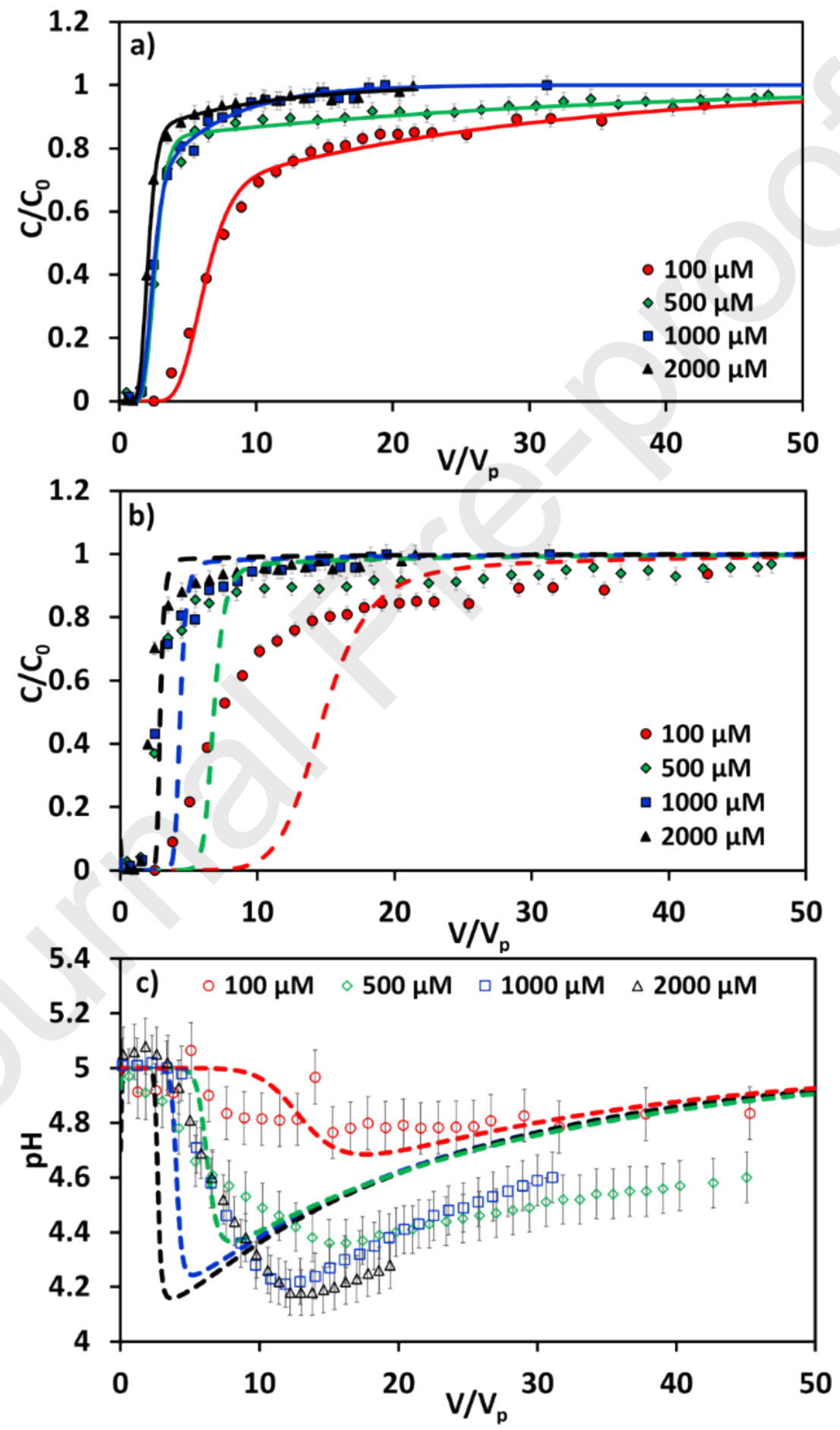

Figure 3. Breakthrough curves for $\mathrm{Si}$ (filled symbols) and $\mathrm{pH}$ (empty symbols) at different influent concentrations of $\mathrm{Si}$ (100, $500,1000,2000 \mu \mathrm{M})$. Inflow conditions: flow rate $=0.5 \mathrm{~mL} / \mathrm{min}, 10 \mathrm{mM} \mathrm{NaCl}$ background electrolyte, pore volume $=3.7 \pm 0.1$ 
$\mathrm{mL}$, inflow $\mathrm{pH} 5.0 \pm 0.1$. Solid lines are calculated breakthrough curves for NA using Hydrus-1D (Fig.3a). Calculated breakthrough curves for $\mathrm{Si}$ (dashed lines) and $\mathrm{pH}$ (dashed lines) using PHREEQC-2 are shown in Fig.3b and Fig.3c, respectively. Here, surface complexation model based on reaction equilibrium was used. The estimated relative uncertainty lied at $3.6 \%$.

To check the time-dependency of Si binding under flow-through conditions, we investigated the response of the BTC of Si on water flow variability (Fig.S3). Lowering pore water velocity to $7.45 \mathrm{~cm} / \mathrm{h}(0.4$ as GCS column porosity) accentuated the sigmoidal shape of the BTC, however with less tailing. This did not, however, significantly influence Si loadings (Fig.S3a). Similar Si loadings $\left(0.25 \mathrm{Si} / \mathrm{nm}^{2}\right.$ for $100 \mu \mathrm{M}$ and $0.6 \mathrm{Si} / \mathrm{nm}^{2}$ for $1000 \mu \mathrm{M}$ ) were achieved when pore water velocity were decreased from $37.3 \mathrm{~cm} / \mathrm{h}$ to 7.5 $\mathrm{cm} / \mathrm{h}$. However, interrupting flow for $24 \mathrm{~h}$ or $72 \mathrm{~h}$ dropped the residual Si concentrations during the no-flow period $\left(0 \mathrm{~cm} / \mathrm{h}\right.$ ), and thus increased loadings to $\sim 1.06 \mathrm{Si} / \mathrm{nm}^{2}$ (Fig. S1 with $1000 \mu \mathrm{M}$ as inflow concentration). Another set of experiments (Fig.S4) at higher influent Si concentration $(2000 \mu \mathrm{M})$ and longer no-flow period (up to 31 days) showed that Si loadings did not exceed $\sim 1.34 \mathrm{Si} / \mathrm{nm}^{2}$. These results suggest that greater Si loadings, through oligomerization/polymerization reactions, can be achieved only upon flow interruption, i.e. under no-flow conditions.

To verify for the lack of local equilibrium in the column system, two modeling approaches were used: (i) a two-site chemical nonequilibrium model combined with a linear sorption isotherm [38], and (ii) a surface complexation model assuming existence of local equilibrium, as commonly used in literature [28,39]. A first-order rate kinetic model implemented in Hydrus-1D (details are given in the SI and Table S6), provides an approximate prediction of the experimental BTC of Si alongside its long tailing (Fig.3a). Thus, this macroscopic approach confirmed that adsorption was kinetically limited, but was not able to predict variations in $\mathrm{pH}$ along the sorption reaction in column. 
Combining surface complexation parameters with only Si monodentate species below $\sim 1 \mathrm{Si} / \mathrm{nm}^{2}$ (Table S2) and transport parameters implemented in PHREEQC-2 did not adequately reproduce the experimental BTC (neither for NA nor pH) (Fig.3b), likely because sorption kinetics were not considered. However, the total Si loadings were well captured by only considering monomer binding (Fig.3b). Collectively, these results suggest that water flow alters Si binding mechanisms, including ligand exchange and oligomerization/polymerization reactions. They also show that no-flow conditions could emulate batch adsorption conditions, as Si loadings were comparable in both settings.

\subsection{Competitive binding of NA and Si onto goethite}

The original asymmetric BTC of NA (Fig.4c) was even steeper when $10 \mu \mathrm{M}$ NA was simultaneously injected with 100-1000 $\mu \mathrm{M}$ Si (Fig. 4a). NA retention did not, however, vary significantly the outflow pH regardless of the presence or absence of silicate (Fig. 4c). In absence of silicate, the long tailing observed in the BTC of NA was likely caused by chemical kinetic limitations. This is supported by the attenuated tail of the NA BTC obtained at a lower flow rate $(0.1 \mathrm{~mL} / \mathrm{min})$ (Fig. S5). 

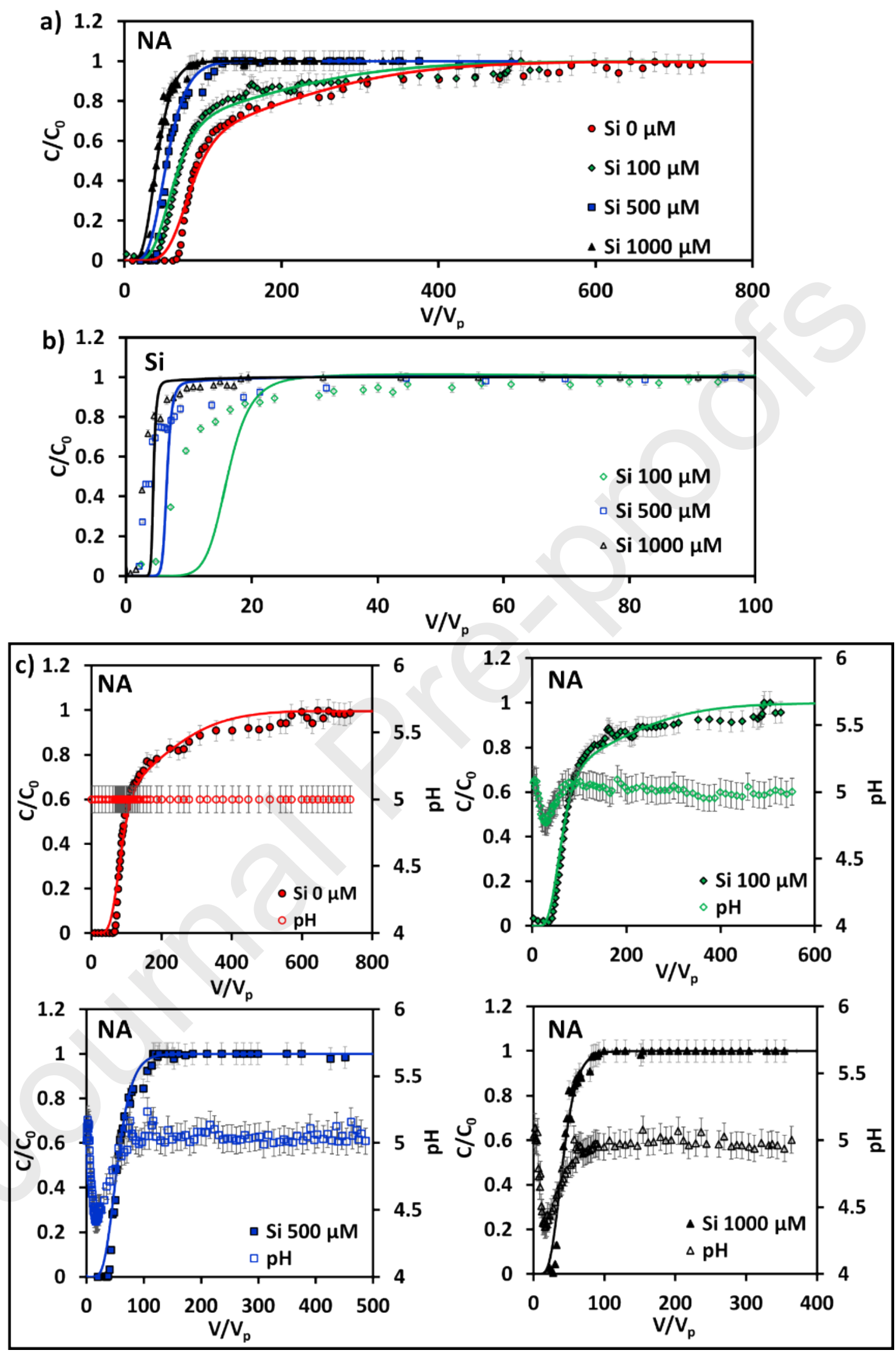
Figure 4. Breakthrough curves for NA (a), Si (b) and pH (c) in simultaneous injection scenarios. Influent solutions containing 10 $\mu \mathrm{M} N A$ and different concentrations of $\mathrm{Si}(0,100,500,1000 \mu \mathrm{M})$ were injected simultaneously. Inflow conditions: flow rate 0.5 $\mathrm{mL} / \mathrm{min}, 10 \mathrm{mM} \mathrm{NaCl}$ background electrolyte, pore volume $=3.7 \pm 0.1 \mathrm{~mL}$, the inflow $\mathrm{pH}$ was $5.0 \pm 0.1$ and slightly varied throughout the breakthrough experiment. Solid lines are calculated breakthrough curves for NA and Si using PHREEQC-2. The estimated relative uncertainty lied at $5 \%$ for NA, and $3.6 \%$ for silicate.

As both NA and Si can bind to goethite through ligand-exchange and hydrogen bonding, competing for the same goethite surface sites should have occurred during simultaneous injection. In particular, ligand exchange reaction with $-\mathrm{OH}$ groups likely drove the first step in the BTC. This aligns with our previous spectroscopic work [20] showing that NA binds both as MB and HB complexes on these sites. At the same time, because we know that $\sim 50 \%$ of these $-\mathrm{OH}$ groups remain unexchanged at $\sim 2 \mathrm{Si} / \mathrm{nm}^{2}$ [17], we expect that competitive NA/Si binding occurred at the first step and this must be the determining factor affecting NA transport.

The BTCs were predicted using surface complexation reactions of NA and Si coupled with a onedimensional transport model in PHREEQC-2. For Si, only the instantaneous formation of monomer surface species was included as the highest Si loading was below $\sim 0.78 \mathrm{Si} / \mathrm{nm}^{2}$. For NA, the surface complexation reactions constants determined in our previous study [21] were used (Table S4), while kinetic rate coefficients were obtained by fitting the experimental BTC $\left(\mathrm{K}_{\mathrm{f}}=0.050 \mathrm{~h}^{-1}\right.$ and $\left.\mathrm{K}_{\mathrm{b}}=0.009 \mathrm{~h}^{-1}\right)$. The used forward and backward rate coefficient for formation of NA metal-bonded surface species were around 10fold lower than those obtained under batch conditions. The detailed fitting procedure is reported in the SI. A good description was obtained for the BTC of NA in absence of Si or at $100 \mu \mathrm{M} \mathrm{Si}$. However, this combined kinetic/SCM model failed to reproduce the sigmoidal BTC of NA at the largest Si concentrations (500 and $1000 \mu \mathrm{M}$ in Fig.S6). The BTC were, however, reproduced by assuming local equilibrium for NA (i.e. no kinetic term is considered, Fig.S7). As a result, kinetic model should only be required to predict experimental BTC with a long tailing, such as in the absence and at low concentrations of Si (Fig.4). 


\subsection{Interactions of NA with goethite-bound Si under dynamic flow conditions}

The transport behavior of NA in columns preloaded in Si was systematically altered in terms of retardation factor and BTC shape (Fig.5a) without, however, any considerable variations in outflow pH (Fig.5b). After pre-equilibrating the column with $\mathrm{Si}\left(0.26,0.58,0.78\right.$ and $\left.\sim 1.30 \mathrm{Si} / \mathrm{nm}^{2}\right)$ and once complete breakthrough was attained, we injected a mixture of $10 \mu \mathrm{MNA}$ and Si at the same concentrations used for the pre-loading step. At low levels of preloaded $\mathrm{Si}\left(0-0.58 \mathrm{Si} / \mathrm{nm}^{2}\right)$, the BTC of NA remained asymmetric with a long tailing. Additionally, NA loadings decreased from $0.25 \mathrm{NA} / \mathrm{nm}^{2}$ to $\sim 0.18 \mathrm{NA} / \mathrm{nm}^{2}$ by adding $0.26 \mathrm{Si} / \mathrm{nm}^{2}$, yet no change in NA loadings $\left(\sim 0.18 \mathrm{NA} / \mathrm{nm}^{2}\right)$ occurred by doubling Si loadings. 

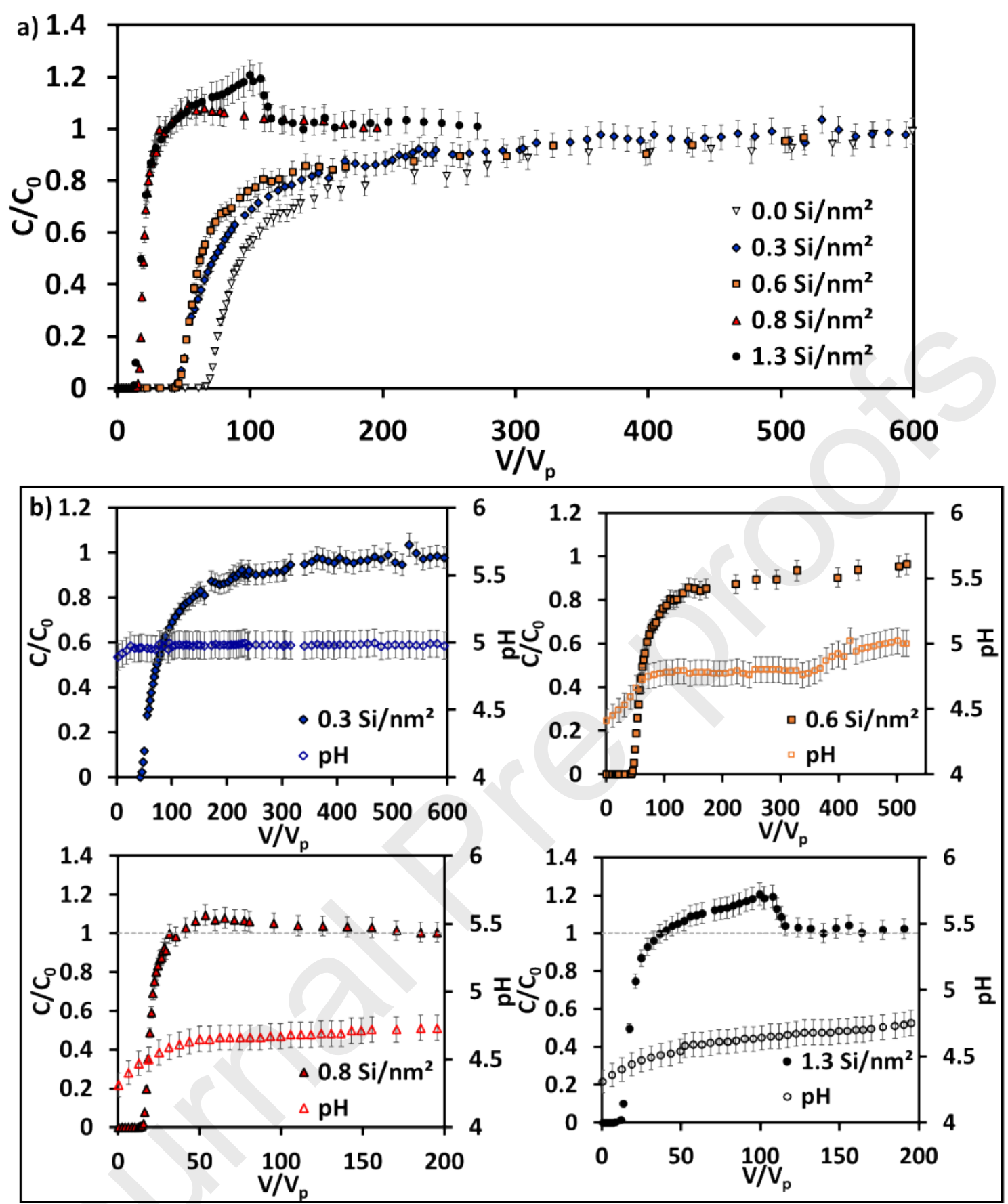

Figure 5. Experimental breakthrough curves for NA (a, b) and $\mathrm{pH}(\mathrm{b})$ in Si-preloaded GCS columns. The columns were initially pre-equilibrated with influent solutions containing different Si concentrations $(0,100$, $500,2000 \mu \mathrm{M}$ ) before injection with solutions of $10 \mu \mathrm{M}$ NA and the corresponding Si concentrations. Inflow conditions: flow rate $0.5 \mathrm{~mL} / \mathrm{min}, 10 \mathrm{mM} \mathrm{NaCl}$ background electrolyte, pore volume $=3.7 \pm 0.1 \mathrm{~mL}$, the inflow $\mathrm{pH}$ was $5.0 \pm 0.1$. The estimated relative uncertainty lied at $5 \%$ for NA.

By comparing the BTCs of NA with $500 \mu \mathrm{M}$ Si in the simultaneous injection scenario with those under the pre-equilibration scenario (Fig.S8), we observed a significant difference in both the sorbed amount and 
the shape of BTC for NA. NA surface loadings decreased from $\sim 0.18$ to $\sim 0.12 \mathrm{NA} / \mathrm{nm}^{2}$ in the simultaneous injection scenario due to the obvious decreased extent of tailing. Suppression of tailing in the BTC for the simultaneous injection scenario suggested, on the other hand, a different binding mechanism of NA. Simultaneous injection of NA $(10 \mu \mathrm{M})$ and $\mathrm{Si}(2000 \mu \mathrm{M})$ in column at high preloaded Si loading $(0.8$ $\mathrm{Si} / \mathrm{nm}^{2}$ ) led first to NA adsorption but thereafter desorption down to $0.02 \mathrm{NA} / \mathrm{nm}^{2}$ (Fig. 5). In columns preloaded with even larger Si loadings $\left(1.30 \mathrm{Si} / \mathrm{nm}^{2}\right)$, injection of NA and Si further decreased NA loading to $0.01 \mathrm{NA} / \mathrm{nm}^{2}$ (Fig.5). The bound NA released in column effluent should likely be replaced by Si species on goethite, further increasing Si loadings in the column. This can be seen experimentally even if the drop in the Si outflow concentration may appear to be not statistically significant (Fig. 6). Indeed, the relative standard deviation calculated on the basis of duplicates breakthrough experiments lied at $3.6 \%$. As our previous work showed Si polymerization reactions can start at loadings exceeding $\sim 1 \mathrm{Si} / \mathrm{nm}^{2}[17]$, we thus suppose that this additional retention may be ascribed to Si oligomerization reactions. The fact that this unexpected phenomenon was only observed with the highest inflow concentration of Si (i.e. $2000 \mu \mathrm{M})$ also supports this hypothesis. 

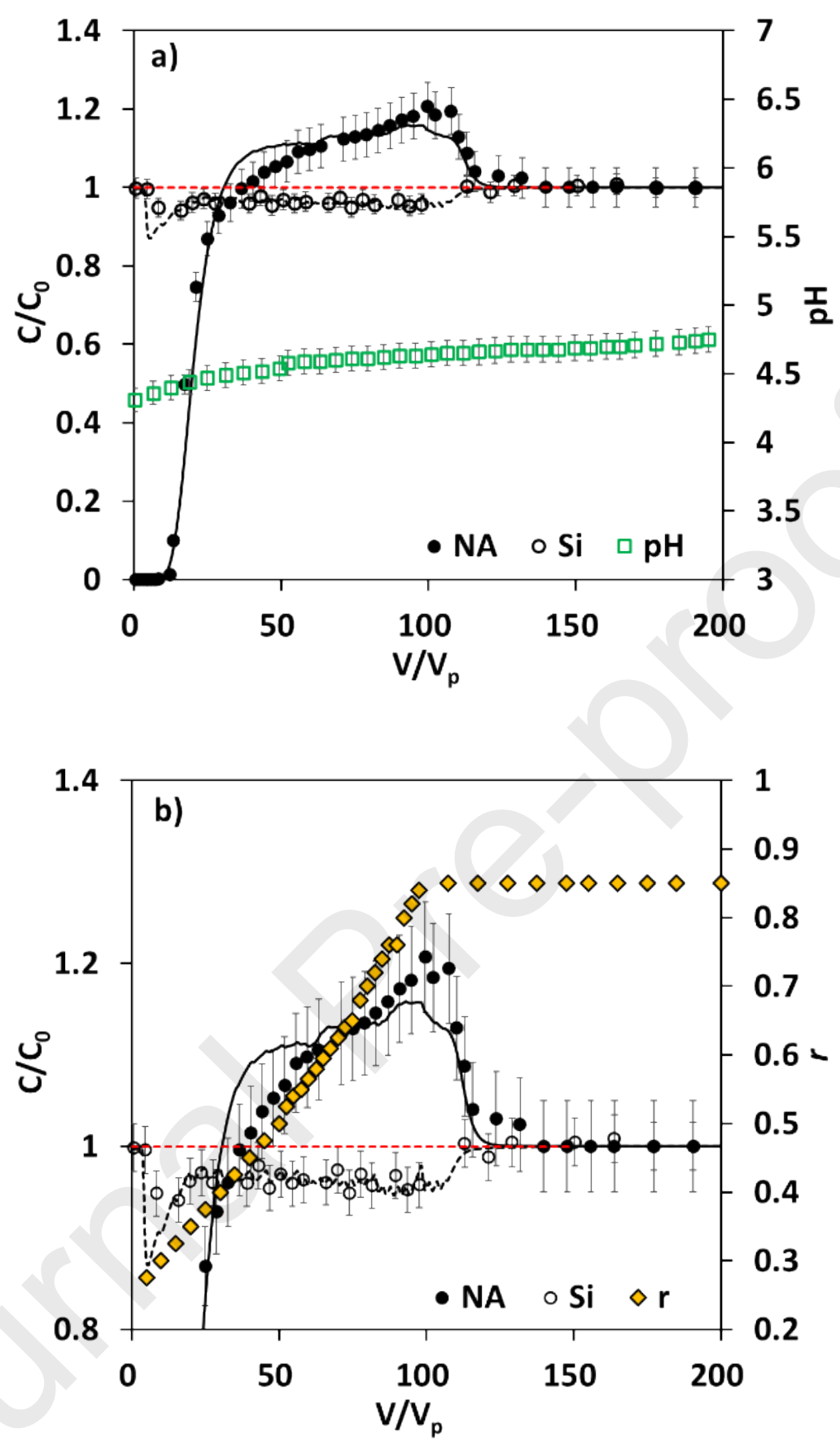

Figure 6. (a) Experimental and calculated breakthrough curves for NA, Si and $\mathrm{pH}$ at the highest initial Si surface loading (1.3 $\mathrm{Si} / \mathrm{nm}^{2}$ ). Inflow conditions: flow rate $0.5 \mathrm{~mL} / \mathrm{min}, 10 \mathrm{mM} \mathrm{NaCl}$ background electrolyte, pore volume $=3.7 \pm 0.1 \mathrm{~mL}$, inflow $\mathrm{pH}$ $5.0 \pm 0.1$. (b) Zoomed portion of the breakthrough curves for NA and Si with variation of $r$. $r$ is the ratio of $\left[\mathrm{Si}(\mathrm{OH})_{4}\right]$ to the sum of $\left[\mathrm{Si}(\mathrm{OH})_{4}\right]$ and $\left[\mathrm{Si}^{*}(\mathrm{OH})_{4}\right]$, specifying the Si concentration at the upper boundary in PHREEQC-2. Solid lines and dash lines are modeling results of NA and Si respectively. Horizontal dashed line represents the complete breakthrough $\left(\mathrm{i} . \mathrm{e} . \mathrm{C} / \mathrm{C}_{0}=1\right)$. The estimated relative uncertainty lied at $5 \%$ for NA, and $3.6 \%$ for silicate. 
As an attempt to verify this hypothesis, we here propose a surface complexation kinetic model for $\mathrm{Si}$ including oligomerization reactions (see section 2.4), however with the instantaneous sorption of NA because of its fast breakthrough. The formation of Si surface oligomers in column was assumed to be kinetically controlled by NA desorption. During the preloading step, we assumed that only intermediate monomeric species formed under dynamic flow conditions (as the oligomerization is supposedly absent), while slight oligomerization may occur during the flow-interruption period. In the subsequent simultaneous injection of NA and $\mathrm{Si}$, reactions for both $\mathrm{Si}^{*}(\mathrm{OH})_{4}$ and $\mathrm{Si}(\mathrm{OH})_{4}$ were considered. The ratio $r=$ $\frac{\left[\mathrm{Si}(\mathrm{OH})_{4}\right]}{\left[\mathrm{Si}^{*}(\mathrm{OH})_{4}\right]+\left[\mathrm{Si}(\mathrm{OH})_{4}\right]}$ was used when setting the upper concentration boundary condition in the model to control the extent of Si surface oligomerization. It is worth noting that the sum of $\left[\mathrm{Si}^{*}(\mathrm{OH})_{4}\right]$ and $\left[\mathrm{Si}(\mathrm{OH})_{4}\right]$ is a constant value, which is equal to the Si concentration $(2000 \mu \mathrm{M}) . r$ is 0 during the preloading step, and tends to 1 to describe the continuous increase in Si surface oligomerization. However, a time-dependent concentration boundary condition was required (i.e. $r$ increases with time) to account for the slow increasing extent of Si surface oligomerization in column. The range of $r$ (Fig. 6b) was estimated by fitting the initial breakthrough point and the peak in the experimental BTC of NA. A sensitivity analysis has also been performed to assess how $r$ influences the shape of BTC of NA (Fig. S9).

Although the calculated curves do not entirely fit the experimental data, our model describes NA release and Si concentration drop (Fig. 6a and 6b). The ease with which both experimental breakthrough curves were fitted by considering oligomerization reactions adds weight to the above-mentioned hypothesis. Therefore, the concomitant NA release and Si adsorption enabling subsequent polymerization is the most plausible explanation for NA mobility in these experiments. It could be that NA facilitated Si polymerization via electron donor-acceptor complexation, as already pointed out for salicylate-silicate complexes [40,41]. Evidence for such interactions is given in difference UV spectra for NA and mixed NA/Si $(2000 \mu \mathrm{M})$ 
solutions (Fig. S10). This charge transfer could have increased the electron density of the terminal Si-OH bond, making it a better acceptor for hydrogen bonding [42]. This interaction would have thereby lowered the activation energy of the rate-limiting step needed for polymerization, making it faster and thus effective under non-equilibrium flow conditions. Molecular-based investigations of silicate-quinolones interactions with goethite are, as such, strongly needed to evaluate these.

\section{Conclusions}

This study contributes to the mounting evidence showing that dissolved silicates can profoundly affect contaminant transport in soil, sediments and groundwater. Here, we show that knowledge of molecular-scale speciation of silicates and a nalidixic acid at mineral surfaces is crucial for accurately describing the retention and transport in reactive porous media. In particular, we showed that Si surface coverage and speciation can be affected by hydrogeochemical conditions. Indeed, flow-through conditions (Darcy velocities of $2.98 \mathrm{~cm} / \mathrm{h}$ and $14.92 \mathrm{~cm} / \mathrm{h}$ ) were not conducive for oligomeric species formation because of kinetic limitations, and only monomeric Si species with loadings of up to $\sim 0.8 \mathrm{Si} / \mathrm{nm}^{2}$ can form at the goethite surfaces. However, water flow variability or discontinuous flow led to high Si loadings. While most of published studies have focused on the adsorption of silicate to mineral surfaces in static suspensions $[2,14,15]$, this work revealed most overlooked aspect of silicate binding under water flow-through conditions, and more specifically the influence of chemical non-equilibrium on the Si surface speciation.

We thereafter showed that the retention of nalidixic acid is lowered at increased inflow Si concentrations because of strong competitive binding of Si towards reactive hydroxo groups. High Si concentrations can even lead to nalidixic acid-induced polymerization of Si. From the literature [41], and our measurements, electron donor-acceptor interactions between silicates and nalidixic acid are likely to have favoured hydrogen bonding between two terminal Si-OH bonds. These could have been the 
mechanisms triggering Si-O-Si bond formation, and have contributed to the complexity of the rate-limited processes leading to the stepwise polymerization of $\mathrm{Si}$.

Failure to account for chemical kinetic limitations may undermine the ability of geochemical transport models for accurately assessing environmental risks or predicting water resources quality. Our work supports the concept that the modification in Si-binding mechanisms under flow-through conditions can alter the mobility of quinolones antibiotic in nature, and thus calls for integrating molecular-level information and kinetics in reactive transport calculations.

Although this work has been focused on nalidixic acid (a first-generation quinolone), our findings may have broader implications and could be extended to other compounds or antibiotics containing carboxylic and amine functional groups. Further investigations are required to address the silicate-organic compounds interactions both in aqueous solution and at mineral surfaces, and extend the reactive transport model to natural porous media.

\section{Supporting Information}

Synthesis and characterization of goethite and goethite coated sand; ATR-FTIR data; equilibrium constant values used in surface complexation model; parameters of inverse modeling approach using two-site linear sorption chemical nonequilibrium model in Hydrus-1D; experimental BTCs of Si with different flow rates and flow-interruption events; calculated BTCs of NA by using equilibrium and kinetic model in PHREEQC2.

\section{Acknowledgements}


This work was supported by the Institut Universitaire de France, the Swedish Research Council (201603808; 2020-04853), the French National Research Agency via the C-FACTOR project (ANR-18-CE010008) and the CNRS (PICS 2018-2020). We gratefully acknowledge the Chinese Scholarship Council of PR China for providing financial support for Lian Zhou to stay at the ENSCR. 


\section{References}

[1] J.D. Hem, Study and interpretation of the chemical characteristics of natural water, Department of the Interior, US Geological Survey, 1985.

[2] T.P. Luxton, C.J. Tadanier, M.J. Eick, Mobilization of Arsenite by Competitive Interaction with Silicic Acid, Soil Sci. Soc. Am. J. 70 (2006) 204-214.

[3] P.J. Swedlund, R.D. Hamid, G.M. Miskelly, Insights into H4SiO4 surface chemistry on ferrihydrite suspensions from ATR-IR, Diffuse Layer Modeling and the adsorption enhancing effects of carbonate, J. Colloid Interface Sci. 352 (2010) 149-157.

[4] The kinetics of silica-water reactions, Geochim. Cosmochim. Acta. 44 (1980) 1683-1699.

[5] Kinetics of quartz dissolution in electrolyte solutions using a hydrothermal mixed flow reactor, Geochim. Cosmochim. Acta. 54 (1990) 955-969.

[6] A.F. White, S.L. Brantley, Chemical weathering rates of silicate minerals, Mineralogical Society of America, Washington, D.C., 1995.

[7] U. Schwertmann, H. Fechter, The point of zero charge of natural and synthetic ferrihydrites and its relation to adsorbed silicate, Clay Miner. 17 (1982) 471-476.

[8] T. Hiemstra, M.O. Barnett, W.H. van Riemsdijk, Interaction of silicic acid with goethite, J. Colloid Interface Sci. 310 (2007) 8-17.

[9] N. Jordan, N. Marmier, C. Lomenech, E. Giffaut, J.-J. Ehrhardt, Sorption of silicates on goethite, hematite, and magnetite: Experiments and modelling, J. Colloid Interface Sci. 312 (2007) 224-229.

[10] X. Yang, P. Roonasi, A. Holmgren, A study of sodium silicate in aqueous solution and sorbed by synthetic magnetite using in situ ATR-FTIR spectroscopy, J. Colloid Interface Sci. 328 (2008) 41-47.

[11] P. Taylor, Interactions of silica with iron oxides: effects on oxide transformations and sorption properties, Atomic Energy of Canada Ltd., 1995.

[12] M.J. Eick, T.P. Luxton, H.A. Welsh, Effect of silica polymerization on the oxalate-promoted dissolution of goethite, Clays Clay Miner. 57 (2009) 578-585.

[13] M.N. Nguyen, F. Picardal, S. Dultz, L. Nguyen-Thanh, T.T.N. Dam, K.M. Nguyen, Effect of silicic acid on the aggregation properties of goethite, Eur. J. Soil Sci. 68 (2017) 650-657.

[14] T. Luxton, M. Eick, D. Rimstidt, The role of silicate in the adsorption/desorption of arsenite on goethite, Chem. Geol. 252 (2008) 125-135.

[15] I. Christl, Y. Brechbühl, M. Graf, R. Kretzschmar, Polymerization of Silicate on Hematite Surfaces and Its Influence on Arsenic Sorption, Environ. Sci. Technol. 46 (2012) 13235-13243.

[16] D. Postma, F. Larsen, N.T. Minh Hue, M.T. Duc, P.H. Viet, P.Q. Nhan, S. Jessen, Arsenic in groundwater of the Red River floodplain, Vietnam: Controlling geochemical processes and reactive transport modeling, Geochim. Cosmochim. Acta. 71 (2007) 5054-5071.

[17] M. Kanematsu, G.A. Waychunas, J.-F. Boily, Silicate Binding and Precipitation on Iron Oxyhydroxides, Environ. Sci. Technol. 52 (2018) 1827-1833.

[18] T. Hiemstra, Ferrihydrite interaction with silicate and competing oxyanions: Geometry and Hydrogen bonding of surface species, Geochim. Cosmochim. Acta. 238 (2018) 453-476.

[19] X. Wang, J.D. Kubicki, J.-F. Boily, G.A. Waychunas, Y. Hu, X. Feng, M. Zhu, Binding Geometries of Silicate Species on Ferrihydrite Surfaces, ACS Earth Space Chem. 2 (2018) 125-134.

[20] J. Xu, R. Marsac, D. Costa, W. Cheng, F. Wu, J.-F. Boily, K. Hanna, Co-Binding of Pharmaceutical Compounds at Mineral Surfaces: Molecular Investigations of Dimer Formation at Goethite/Water Interfaces, Environ. Sci. Technol. 51 (2017) 8343-8349.

[21] J. Xu, R. Marsac, C. Wei, F. Wu, J.-F. Boily, K. Hanna, Cobinding of Pharmaceutical Compounds at 
Mineral Surfaces: Mechanistic Modeling of Binding and Cobinding of Nalidixic Acid and Niflumic Acid at Goethite Surfaces, Environ. Sci. Technol. 51 (2017) 11617-11624.

[22] D.L. Parkhurst, C.A.J. Appelo, User's guide to PHREEQC (Version 2): A computer program for speciation, batch-reaction, one-dimensional transport, and inverse geochemical calculations, WaterResour. Investig. Rep. 99 (1999) 312.

[23] W. Cheng, L. Zhou, R. Marsac, J.-F. Boily, K. Hanna, Effects of organic matter-goethite interactions on reactive transport of nalidixic acid: Column study and modeling, Environ. Res. 191 (2020) 110187.

[24] I. Halasz, M. Agarwal, R. Li, N. Miller, Vibrational spectra and dissociation of aqueous $\mathrm{Na}_{2} \mathrm{SiO}_{3}$ solutions, Catal. Lett. 117 (2007) 34-42.

[25] F. Gaboriaud, J.-J. Ehrhardt, Effects of different crystal faces on the surface charge of colloidal goethite $(\alpha-\mathrm{FeOOH})$ particles: an experimental and modeling study, Geochim. Cosmochim. Acta. 67 (2003) 967983.

[26] B. Rusch, K. Hanna, B. Humbert, Coating of quartz silica with iron oxides: Characterization and surface reactivity of iron coating phases, Colloids Surf. Physicochem. Eng. Asp. 353 (2010) 172-180.

[27] K. Hanna, J.-F. Boily, Sorption of Two Naphthoic Acids to Goethite Surface under Flow through Conditions, Environ. Sci. Technol. 44 (2010) 8863-8869.

[28] K. Hanna, S. Martin, F. Quilès, J.-F. Boily, Sorption of Phthalic Acid at Goethite Surfaces under FlowThrough Conditions, Langmuir. 30 (2014) 6800-6807.

[29] L. Zhou, S. Martin, W. Cheng, L. Lassabatere, J.-F. Boily, K. Hanna, Water Flow Variability Affects Adsorption and Oxidation of Ciprofloxacin onto Hematite, Environ. Sci. Technol. 53 (2019) 1010210109.

[30] A.E. Greenberg, L.S. Clesceri, A.D. Eaton, Standard Methods for the Examination of Water and Wastewater, American Public Health Association, 1992.

[31] G.S. Pokrovski, J. Schott, F. Farges, J.-L. Hazemann, Iron (III)-silica interactions in aqueous solution: insights from X-ray absorption fine structure spectroscopy, Geochim. Cosmochim. Acta. 67 (2003) 3559-3573.

[32] T. Hiemstra, W.H. Van Riemsdijk, A Surface Structural Approach to Ion Adsorption: The Charge Distribution (CD) Model, J. Colloid Interface Sci. 179 (1996) 488-508.

[33] T. Hiemstra, W.H. Van Riemsdijk, A surface structural approach to ion adsorption: the charge distribution (CD) model, J. Colloid Interface Sci. 179 (1996) 488-508.

[34] R. Marsac, S. Martin, J.-F. Boily, K. Hanna, Oxolinic Acid Binding at Goethite and Akaganéite Surfaces: Experimental Study and Modeling, Environ. Sci. Technol. 50 (2016) 660-668.

[35] W. Stumm, J.J. Morgan, Aquatic chemistry: chemical equilibria and rates in natural waters, 3rd ed, Wiley, New York, 1996.

[36] K. Axe, P. Persson, Time-dependent surface speciation of oxalate at the water-boehmite $(\gamma-\mathrm{AlOOH})$ interface: implications for dissolution, Geochim. Cosmochim. Acta. 65 (2001) 4481-4492.

[37] H.P. van Leeuwen, Eigen Kinetics in Surface Complexation of Aqueous Metal Ions, Langmuir. 24 (2008) $11718-11721$.

[38] J. Šimůnek, M.Th. van Genuchten, M. Sejna, Development and applications of the HYDRUS and STANMOD software packages and related codes, Vadose Zone J. 7 (2008) 587-600.

[39] D. Montalvo, E. Smolders, Metals and Metalloid Removal by Colloidal Humic Acid-Goethite: Column Experiments and Geochemical Modeling, Vadose Zone J. 18 (2019) 190004.

[40] P.C. Bennett, M.E. Melcer, D.I. Siegel, J.P. Hassett, The dissolution of quartz in dilute aqueous solutions of organic acids at $25^{\circ} \mathrm{C}$, Geochim. Cosmochim. Acta. 52 (1988) 1521-1530.

[41] P. Bennett, D.I. Siegel, Increased solubility of quartz in water due to complexing by organic compounds, 
Nature. 326 (1987) 684-686.

[42] S. Grabowsky, M.F. Hesse, C. Paulmann, P. Luger, J. Beckmann, How to Make the Ionic Si-O Bond More Covalent and the $\mathrm{Si}-\mathrm{O}-\mathrm{Si}$ Linkage a Better Acceptor for Hydrogen Bonding, Inorg. Chem. 48 (2009) 4384-4393.

\section{Highlights}

- Novel mathematical model combining kinetics and surface complexation reactions is developed.

- Flowing water alters Si binding mechanisms onto $\alpha-\mathrm{FeOOH}$.

- Si monomeric species occupy no more than $\sim 22 \%$ of the reactive $\mathrm{OH}$ groups on goethite.

- Surface oligomerization/polymerization is a rate-limited process in column.

- Stepwise polymerization of silicate is crucial to adequately predicting the reactive transport of quinolones. 


\section{Graphical Abstract}

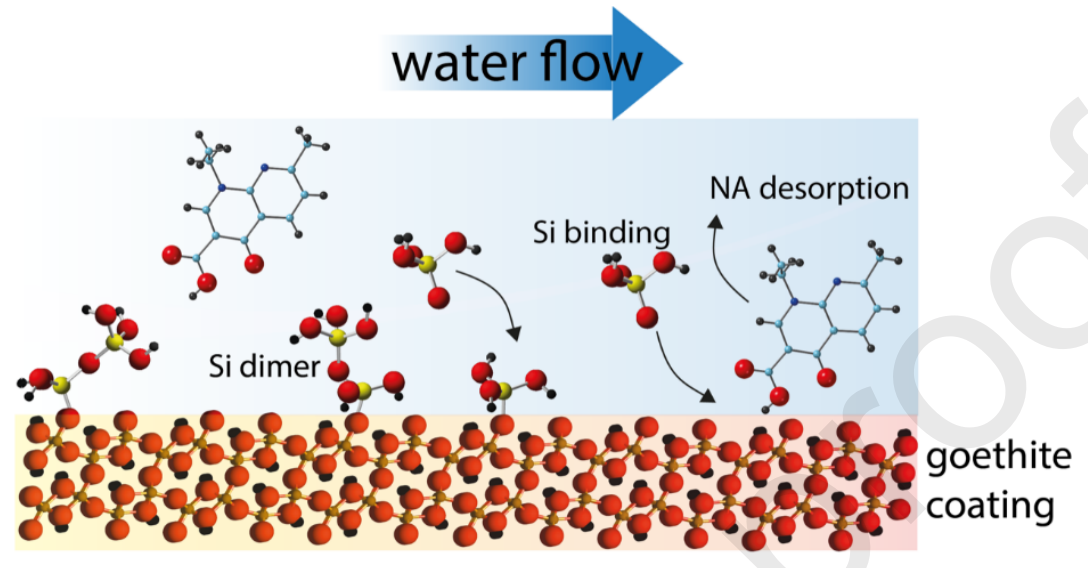




\section{Credit Author Statement:}

LZ, RM, JFB and KH designed the study. LZ and WC carried out the experiments and wrote the original draft. LZ performed the calculations. JFB and KH wrote, reviewed and edited the manuscript. All authors discussed the results and commented on the manuscript. 


\section{Declaration of interests}

$\bigotimes$ The authors declare that they have no known competing financial interests or personal relationships that could have appeared to influence the work reported in this paper.

$\square$ The authors declare the following financial interests/personal relationships which may be considered as potential competing interests: 